Supporting Information for:

\title{
Metal-Only Lewis Pairs Based on Zerovalent Osmium
}

Robin Bissert, Holger Braunschweig, ${ }^{*}$ Rian D. Dewhurst, Christoph Schneider

Institut für Anorganische Chemie, Julius-Maximilians-Universität Würzburg, Am Hubland, 97074

Würzburg. E-mail: h.braunschweig@uni-wuerzburg.de 
NMR spectra of prepared compounds

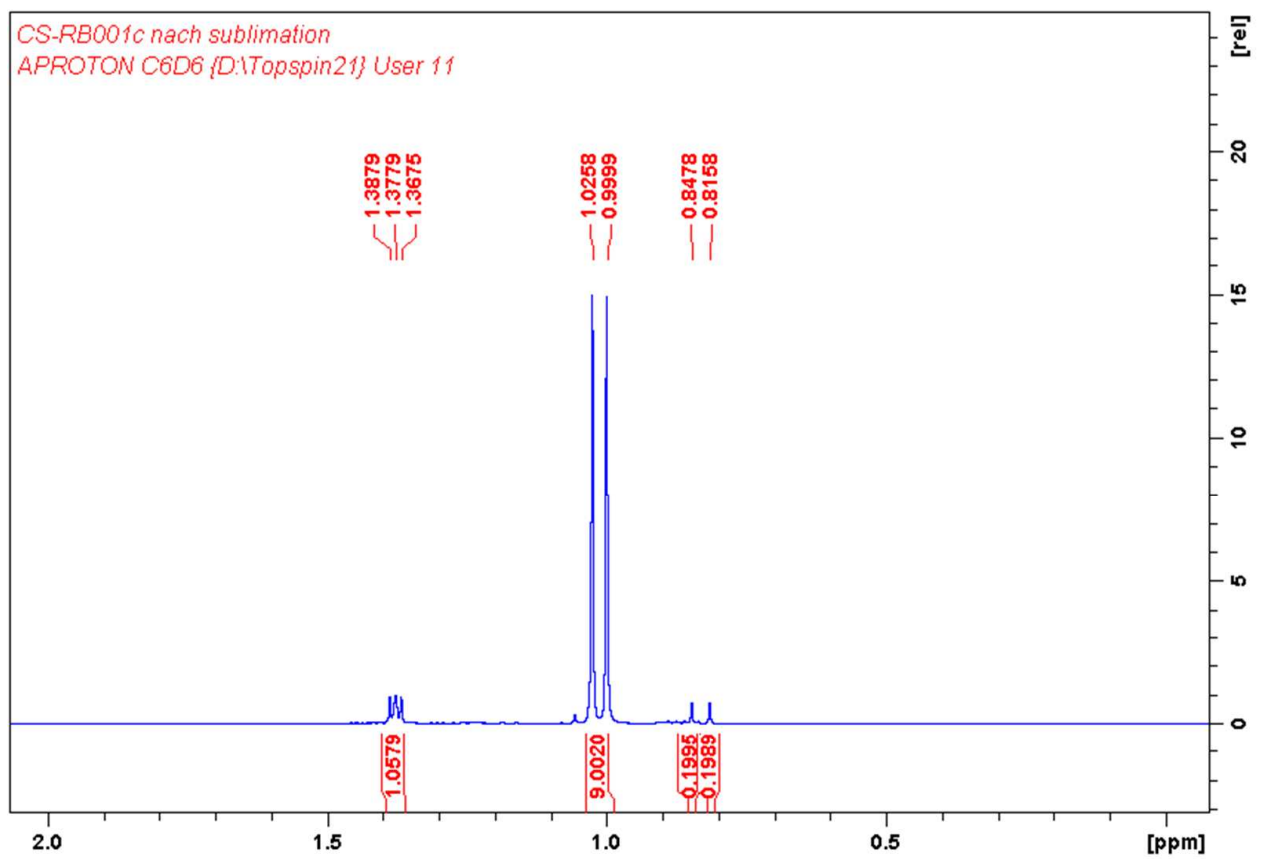

Figure S1. ${ }^{1} \mathrm{H}$ NMR spectrum of 1a. The triplet at 1.37 represents traces of $\left[\mathrm{Os}(\mathrm{CO})_{3}\left(\mathrm{PMe}_{3}\right)_{2}\right]$ and the doublet at 0.83 represents traces of $\left[\mathrm{Os}_{3}(\mathrm{CO})_{11}\left(\mathrm{PMe}_{3}\right)\right]$.

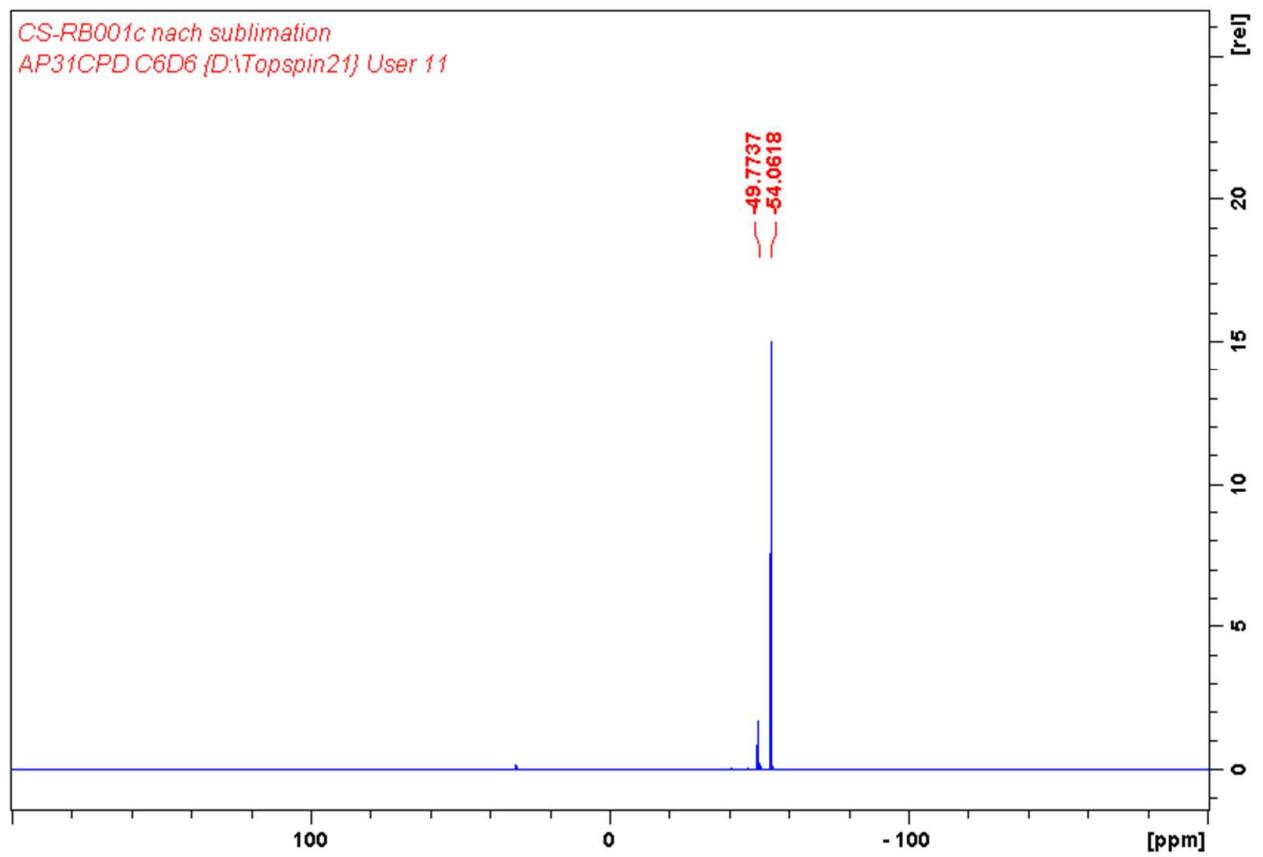

Figure S2. ${ }^{31} \mathrm{P}\left\{{ }^{1} \mathrm{H}\right\}$ NMR spectrum of 1a. The signal at -49.7 represents traces of $\left[\mathrm{Os}(\mathrm{CO})_{3}\left(\mathrm{PMe}_{3}\right)_{2}\right]$. 


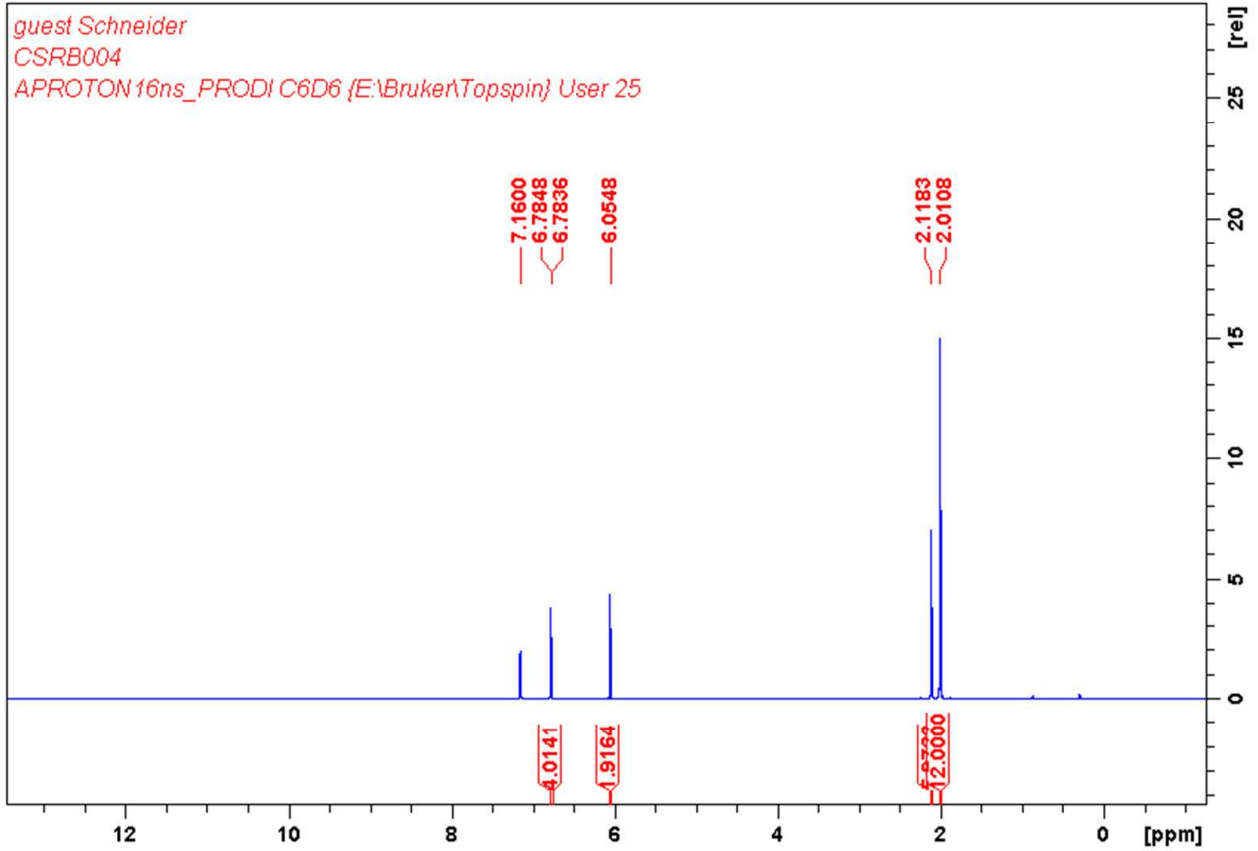

Figure S3. ${ }^{1} \mathrm{H}$ NMR spectrum of $\mathbf{1 b}$. The signal at 7.16 represents the $\mathrm{C}_{6} \mathrm{D}_{6}$ signal.

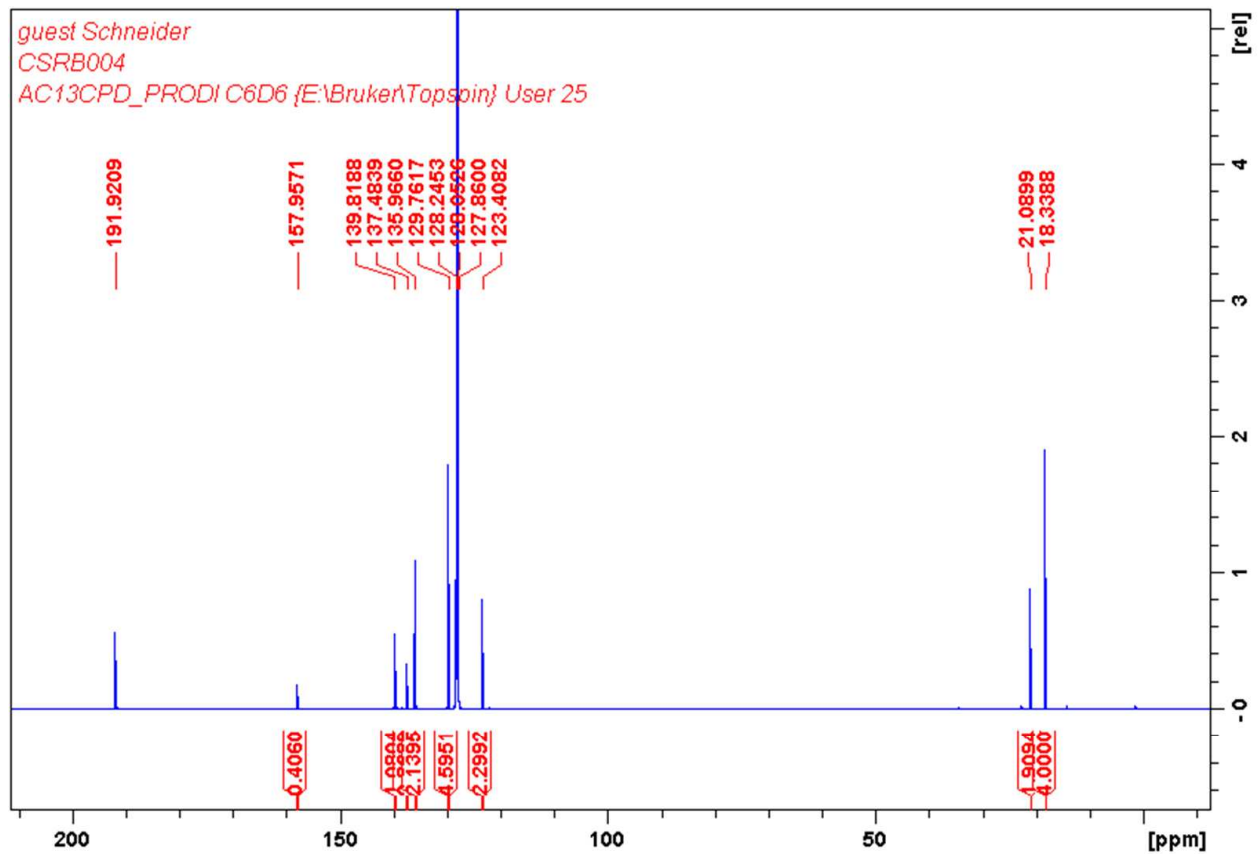

Figure S4. ${ }^{13} \mathrm{C}\left\{{ }^{1} \mathrm{H}\right\}$ NMR spectrum of $\mathbf{1 b}$. The signal at 128.05 represents the $\mathrm{C}_{6} \mathrm{D}_{6}$ signal. 


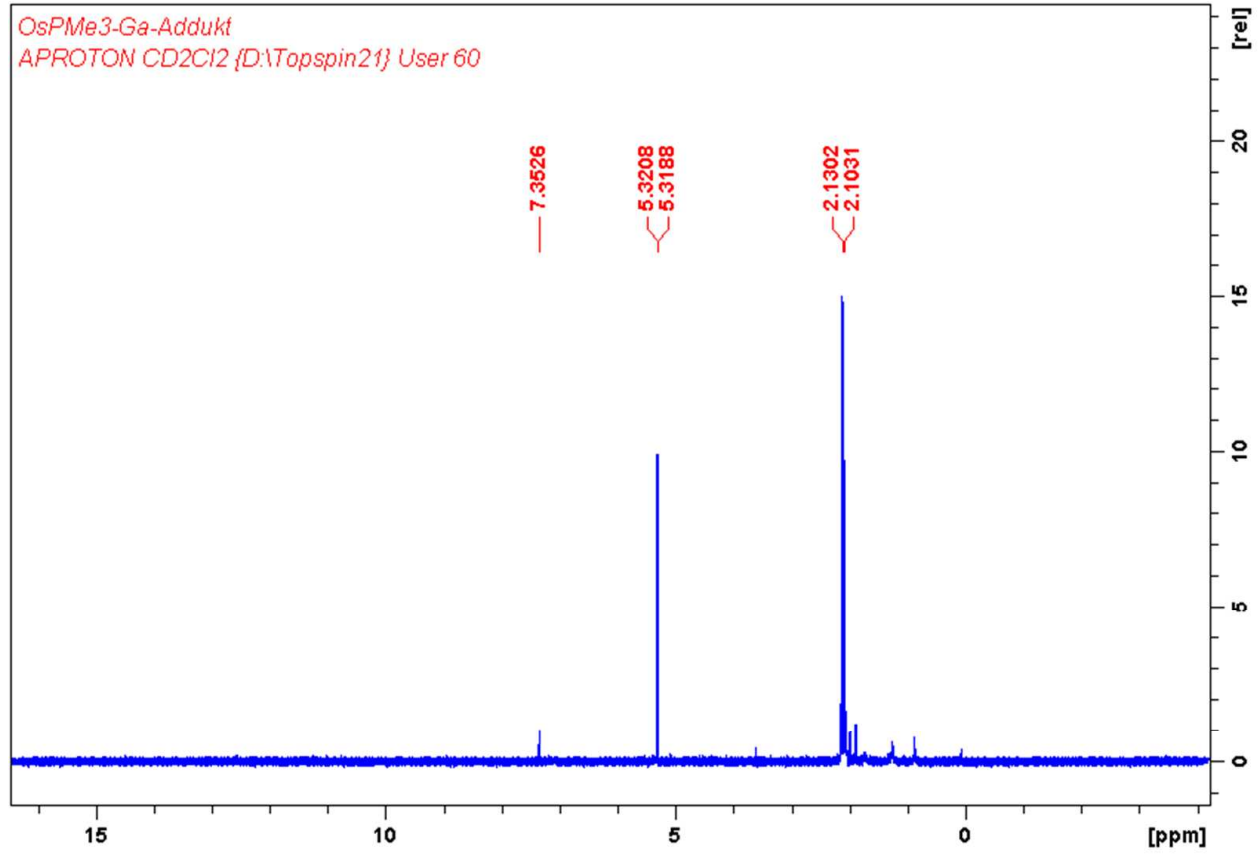

Figure S5. ${ }^{1} \mathrm{H}$ NMR spectrum of $\mathbf{2 a}$. The signal at 5.32 represents the $\mathrm{CD}_{2} \mathrm{Cl}_{2}$ signal and the signal at 7.35 can be assigned to benzene from the preparation.

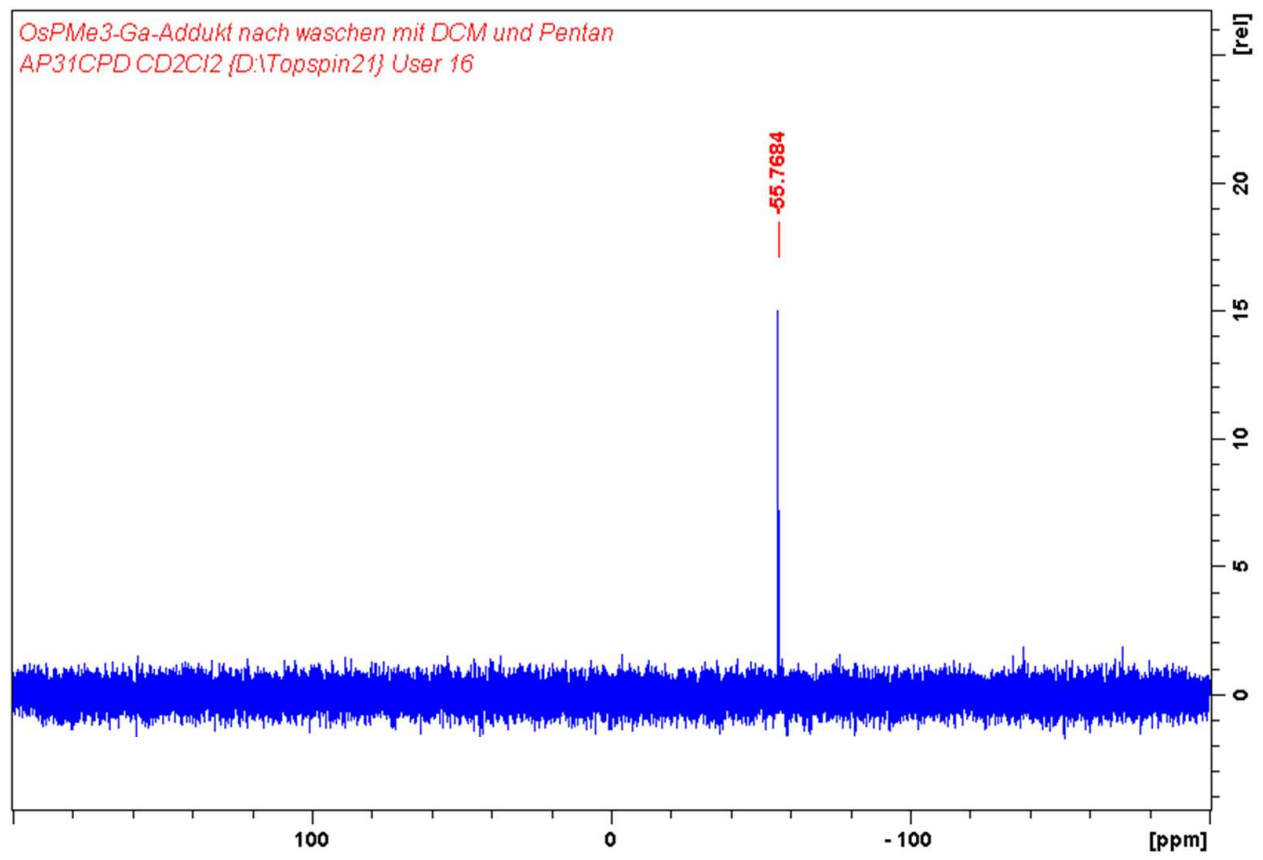

Figure S6. ${ }^{31} \mathrm{P}\left\{{ }^{1} \mathrm{H}\right\}$ NMR spectrum of $\mathbf{2 a}$. 


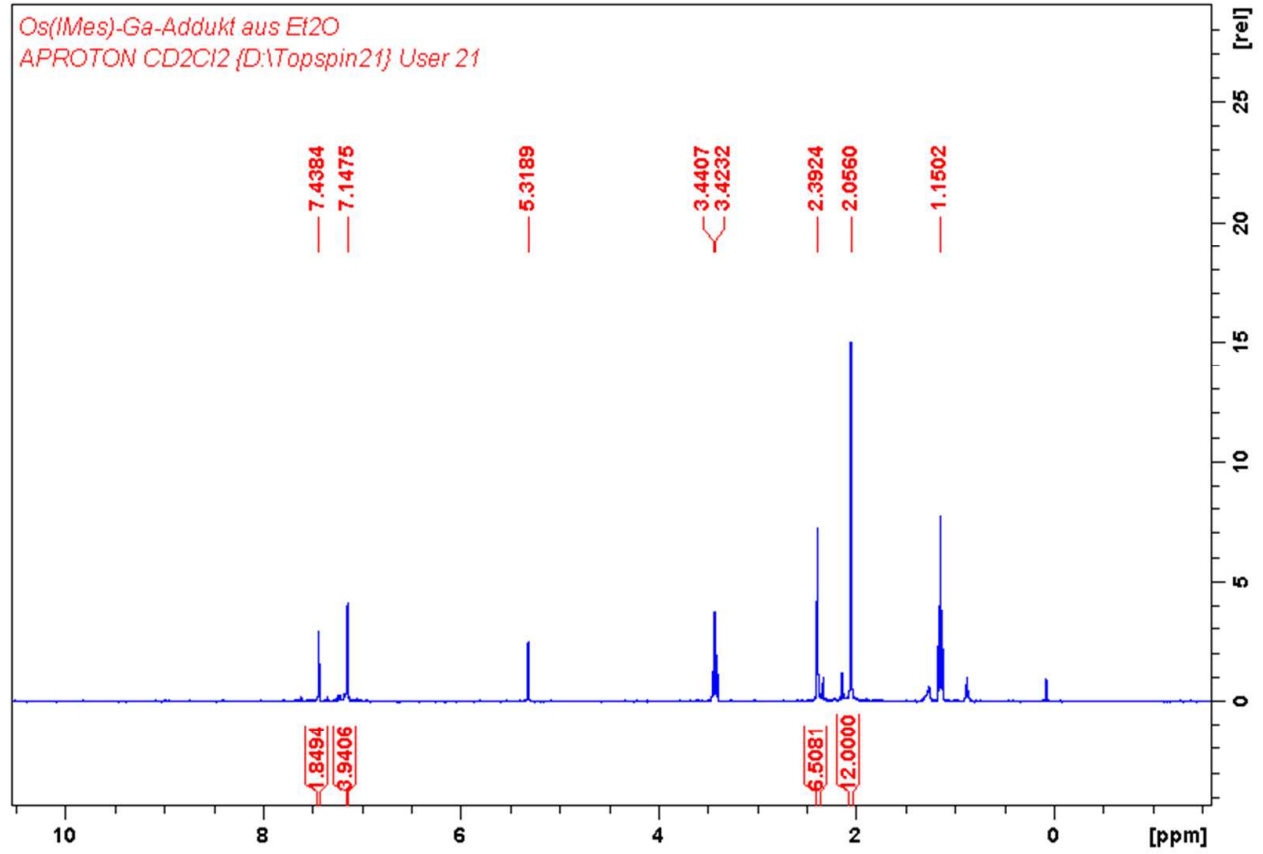

Figure S7. ${ }^{1} \mathrm{H}$ NMR spectrum of $\mathbf{2 b}$. The signal at 5.32 represents the $\mathrm{CD}_{2} \mathrm{Cl}_{2}$ signal and the signals at 3.44 and 1.15 can be assigned to benzene from the preparation.

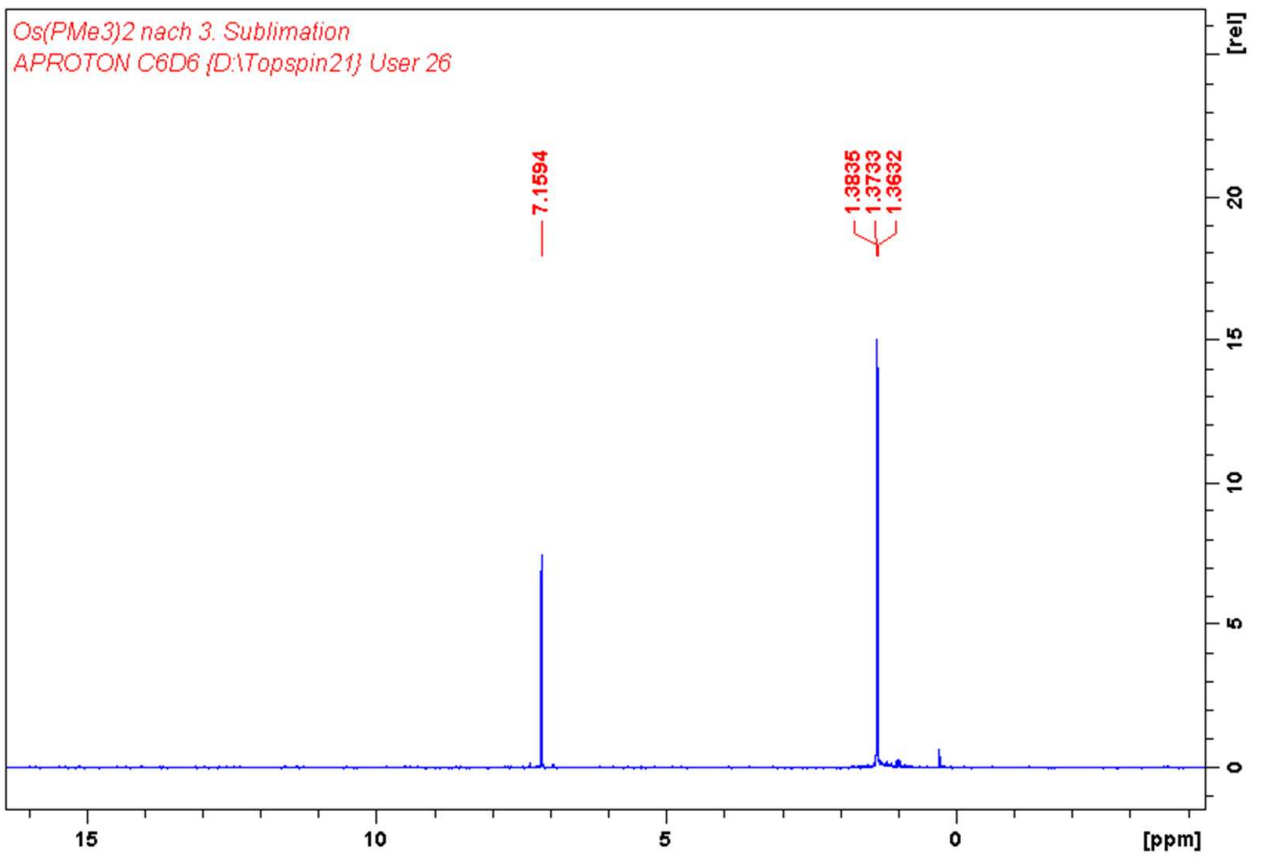

Figure S8. ${ }^{1} \mathrm{H}$ NMR spectrum of 1 c. The signal at 7.16 represents the $\mathrm{C}_{6} \mathrm{D}_{6}$ signal. 


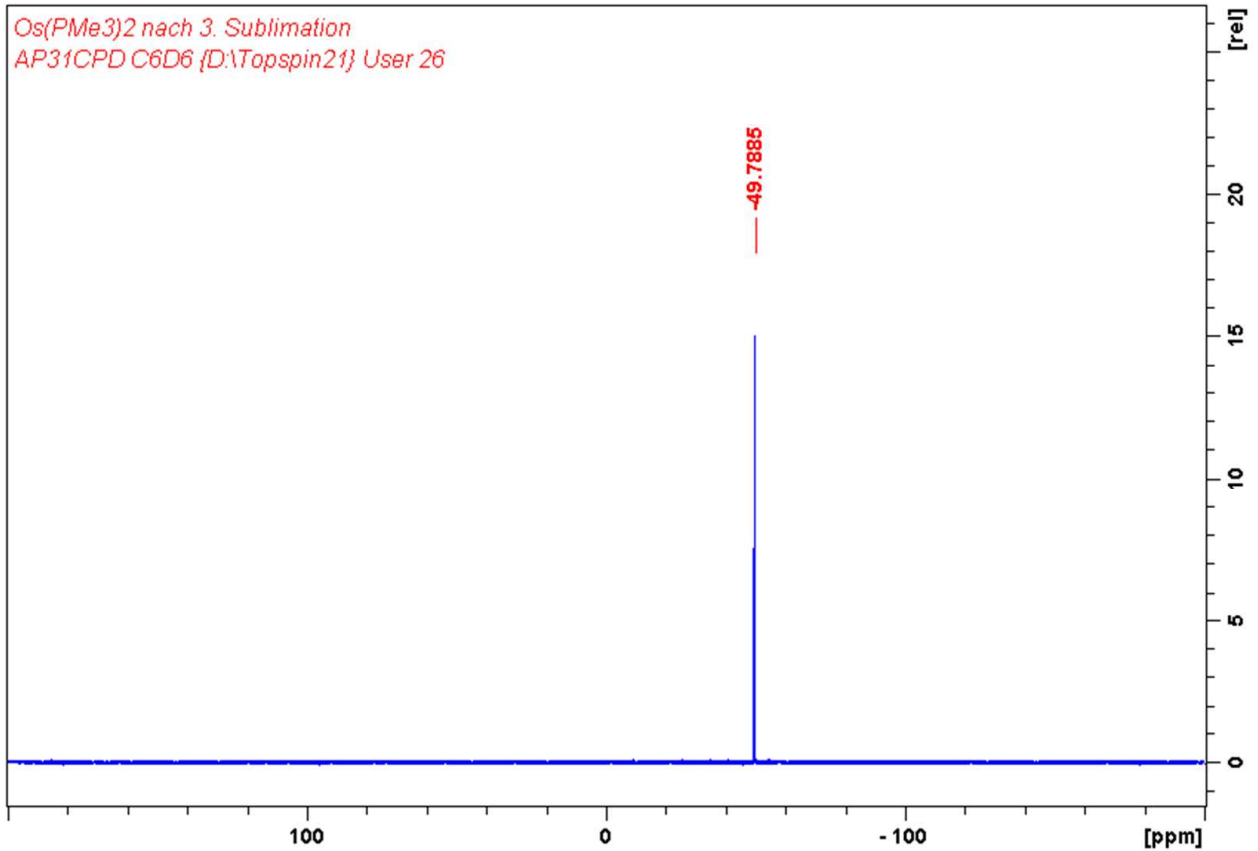

Figure S9. ${ }^{31} \mathrm{P}\left\{{ }^{1} \mathrm{H}\right\}$ NMR spectrum of $\mathbf{1 c}$.

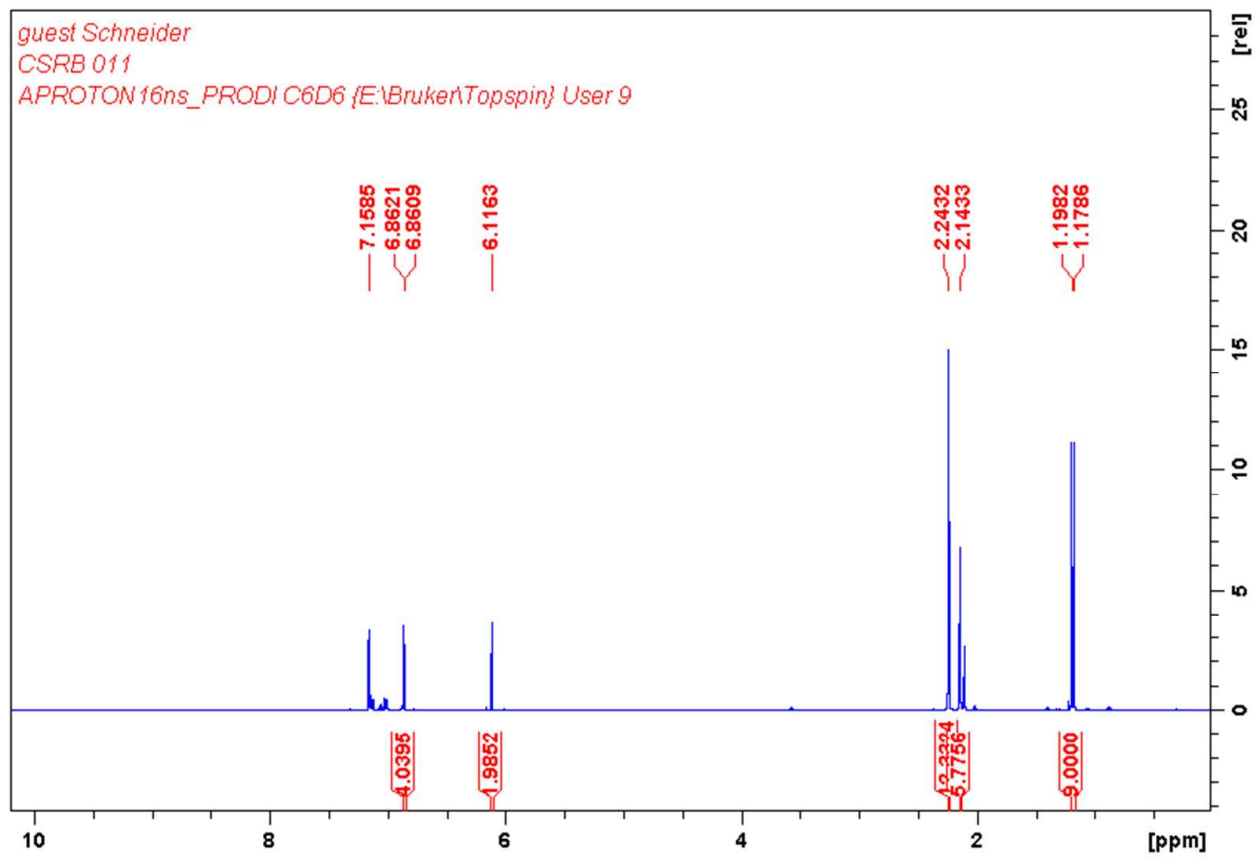

Figure S10. ${ }^{1} \mathrm{H}$ NMR spectrum of $\mathbf{1 d}$. The signal at 7.16 represents the $\mathrm{C}_{6} \mathrm{D}_{6}$ signal. 


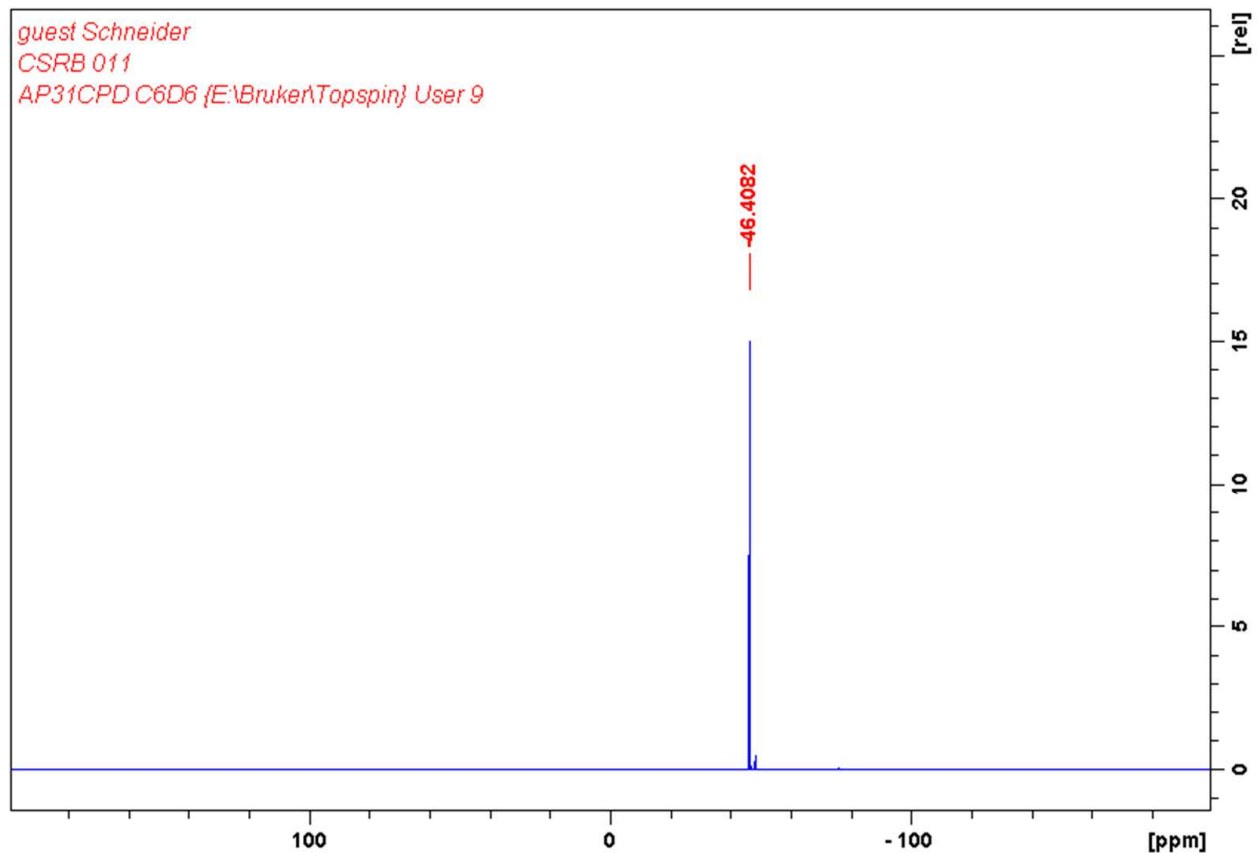

Figure S11. ${ }^{31} \mathrm{P}\left\{{ }^{1} \mathrm{H}\right\}$ NMR spectrum of $\mathbf{1 d}$.

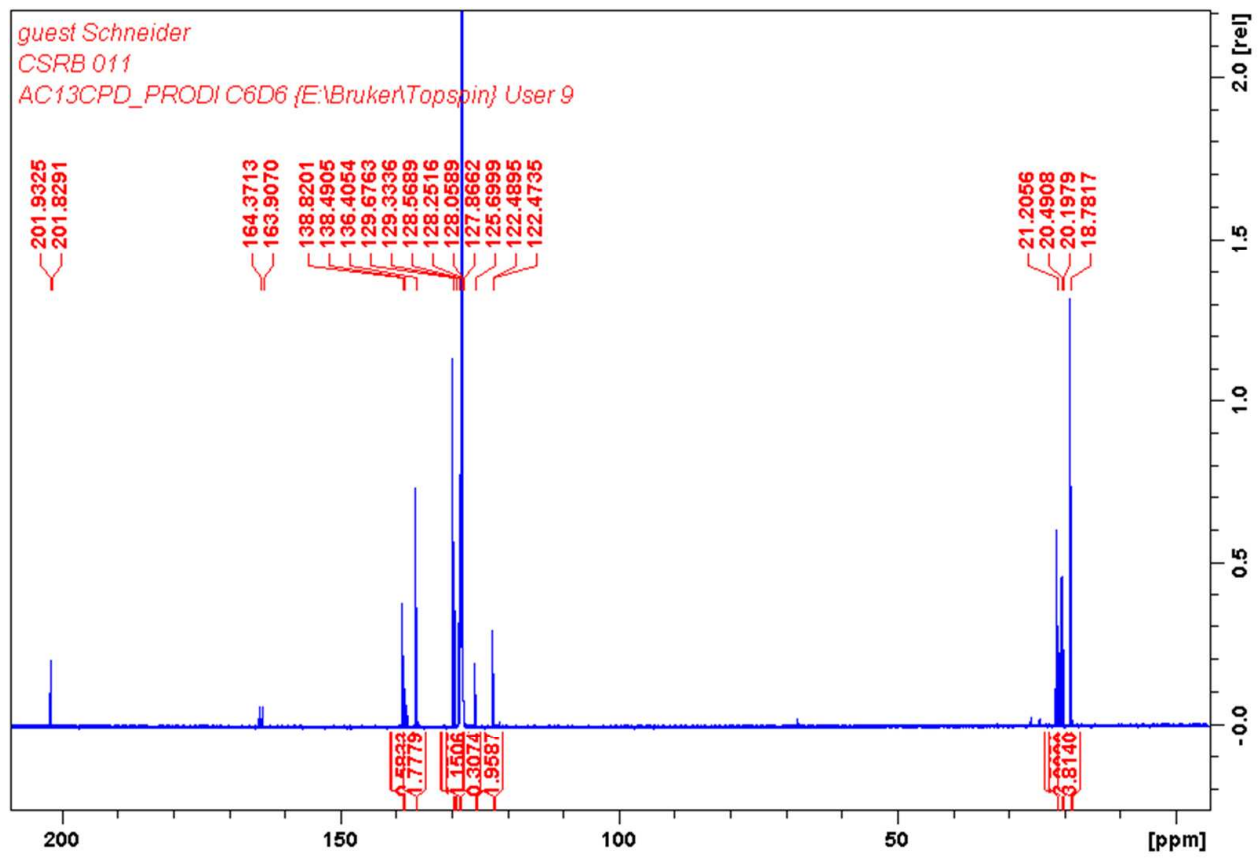

Figure S12. ${ }^{13} \mathrm{C}\left\{{ }^{1} \mathrm{H}\right\}$ NMR spectrum of $\mathbf{1 d}$. The signal at 128.05 represents the $\mathrm{C}_{6} \mathrm{D}_{6}$ signal. 


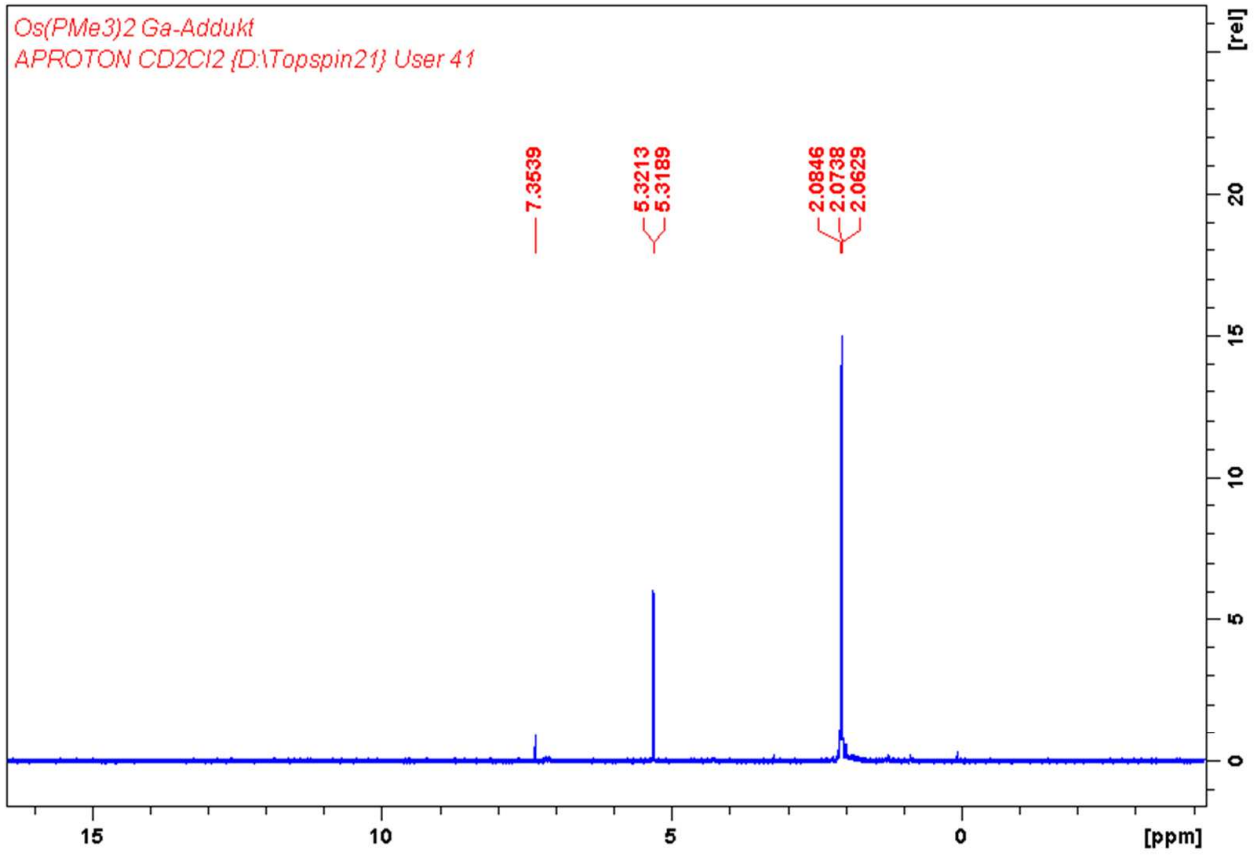

Figure S13. ${ }^{1} \mathrm{H}$ NMR spectrum of 2c. The signal at 5.32 represents the $\mathrm{CD}_{2} \mathrm{Cl}_{2}$ signal and the signal at 7.35 can be assigned to benzene from the preparation.

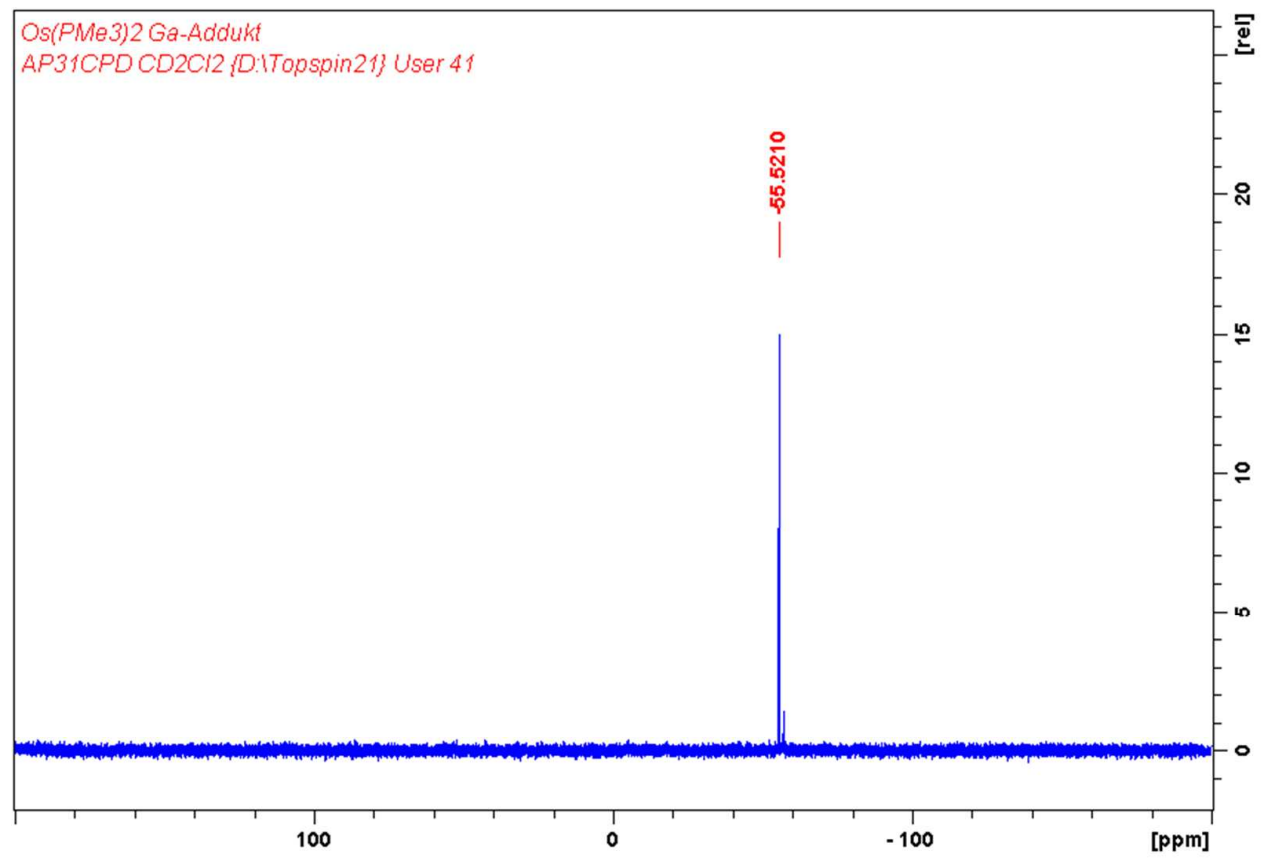

Figure S14. ${ }^{31} \mathrm{P}\left\{{ }^{1} \mathrm{H}\right\}$ NMR spectrum of $\mathbf{2 c}$. 


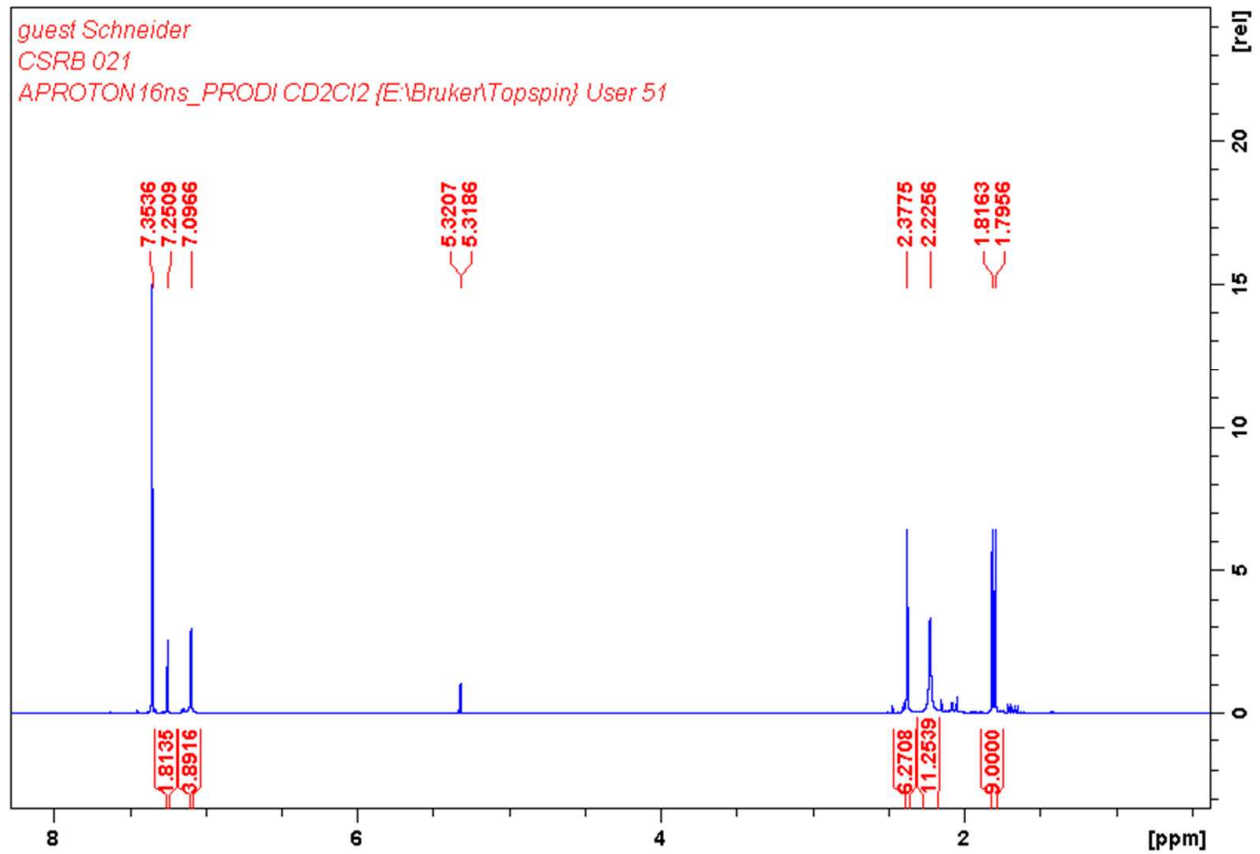

Figure S15. ${ }^{1} \mathrm{H}$ NMR spectrum of $\mathbf{2 d}$. The signal at 5.32 represents the $\mathrm{CD}_{2} \mathrm{Cl}_{2}$ signal and the signal at 7.35 can be assigned to benzene from the preparation.

${ }^{31} P\left\{{ }^{l} H\right\}$ NMR spectrum

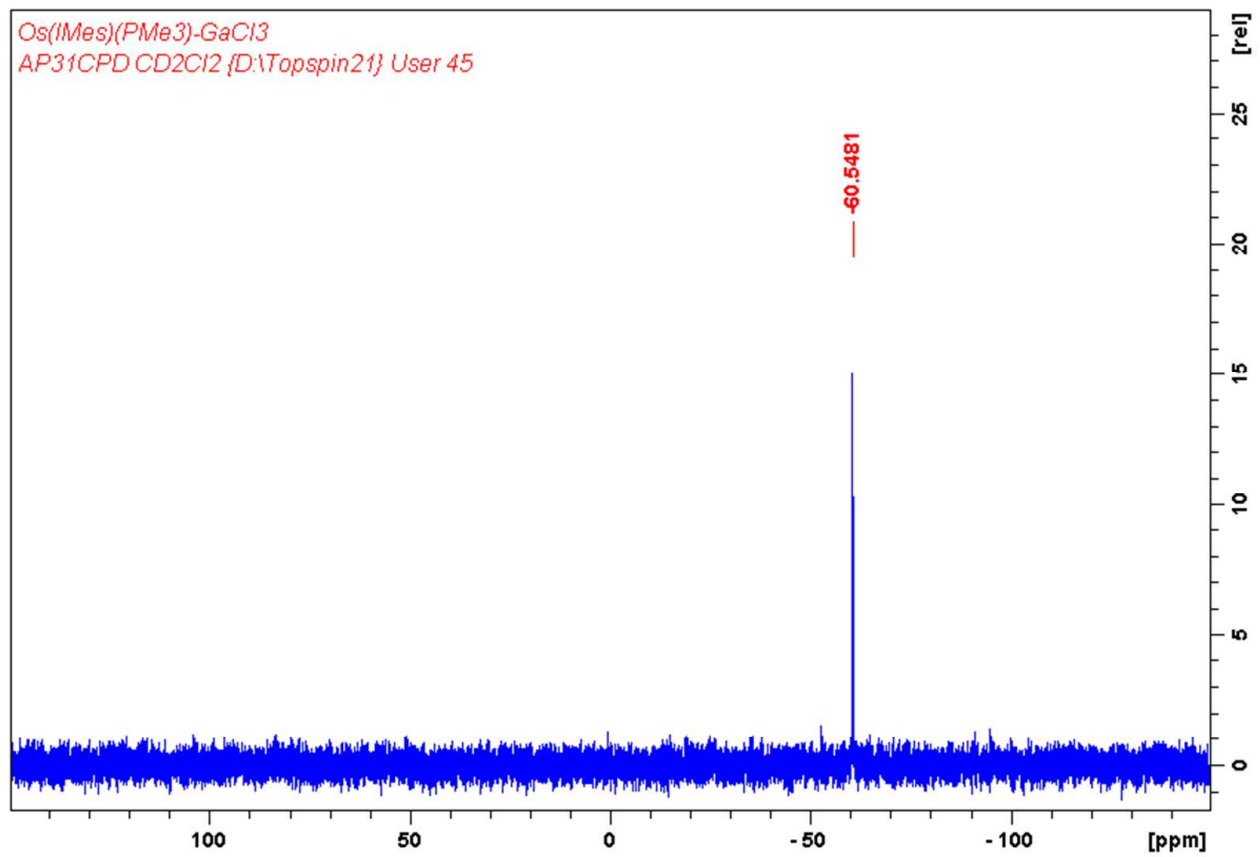

Figure S16. ${ }^{31} \mathrm{P}\left\{{ }^{1} \mathrm{H}\right\}$ NMR spectrum of $\mathbf{2 d}$. 


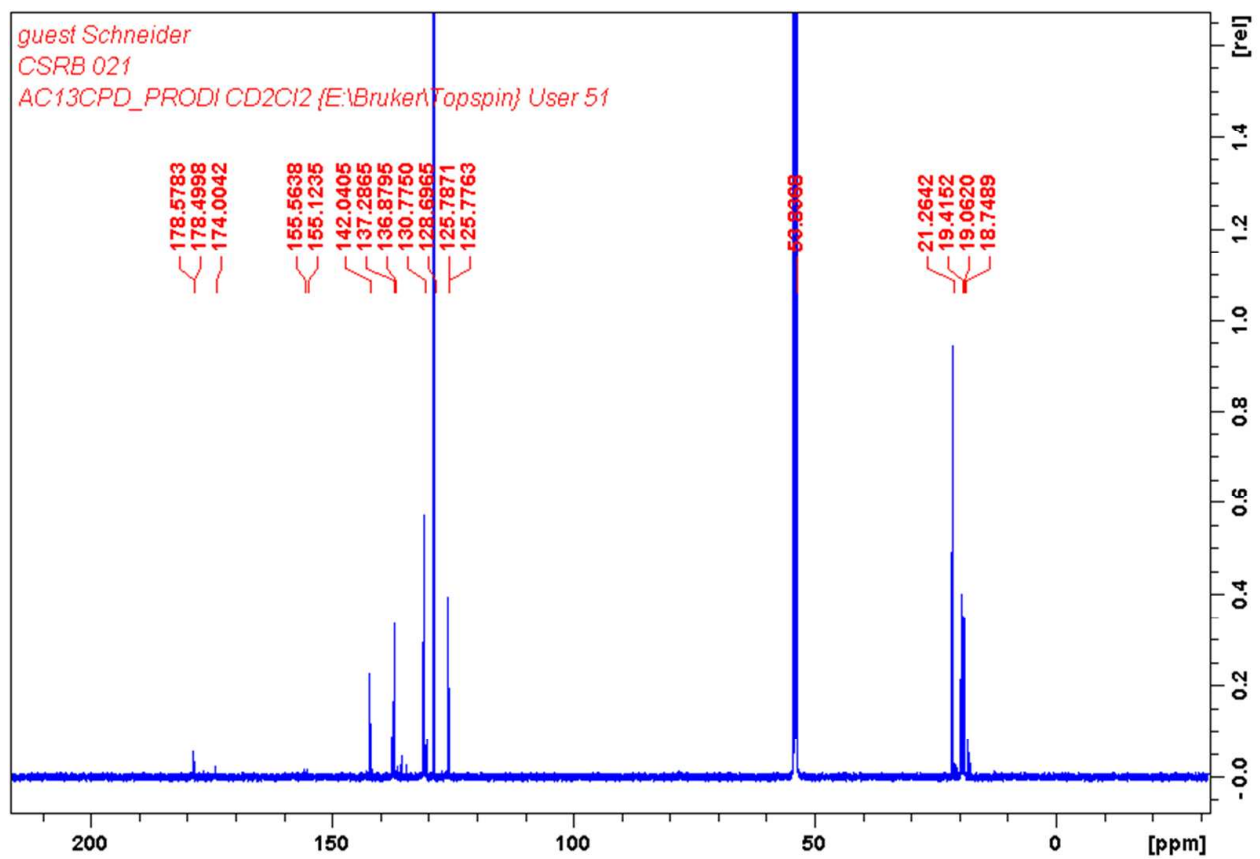

Figure S17. ${ }^{13} \mathrm{C}\left\{{ }^{1} \mathrm{H}\right\}$ NMR spectrum of $2 d$. The signal at 53.84 represents the $\mathrm{CD}_{2} \mathrm{Cl}_{2}$ signal and the signal at 128.69 can be assigned to benzene from the preparation.

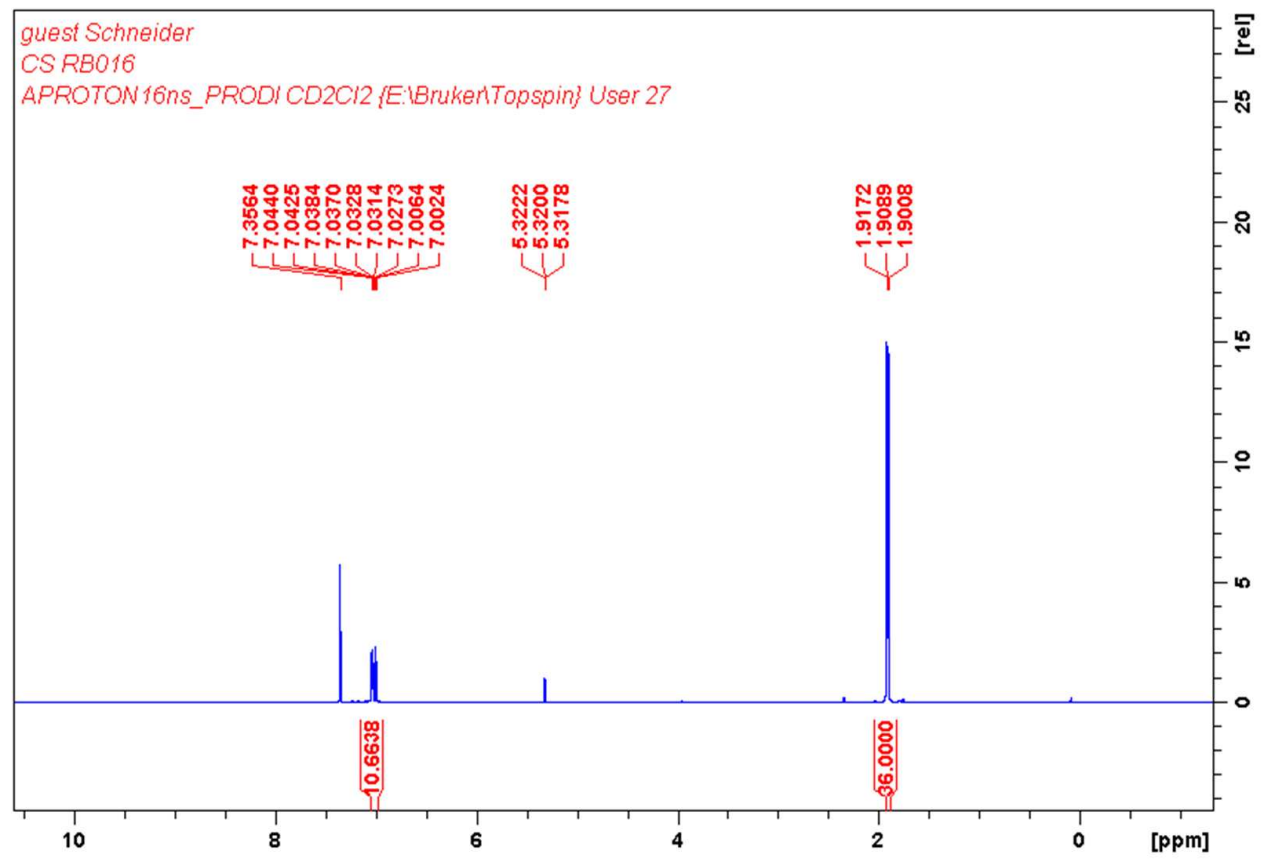

Figure S18. ${ }^{1} \mathrm{H}$ NMR spectrum of 2e. The signal at 5.32 represents the $\mathrm{CD}_{2} \mathrm{Cl}_{2}$ signal and the signal at 7.35 can be assigned to benzene from the preparation. 


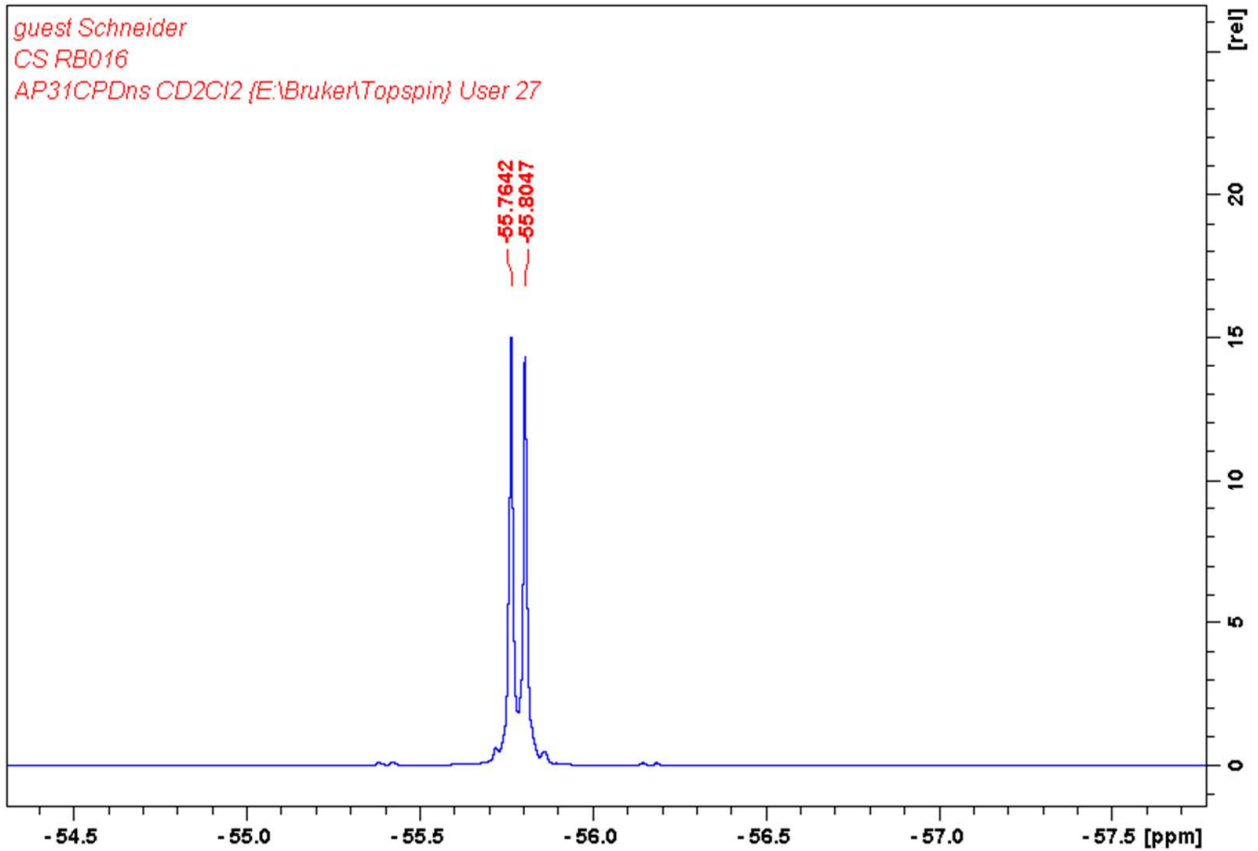

Figure S19. ${ }^{31} \mathrm{P}\left\{{ }^{1} \mathrm{H}\right\}$ NMR spectrum of $\mathbf{2 e}$.

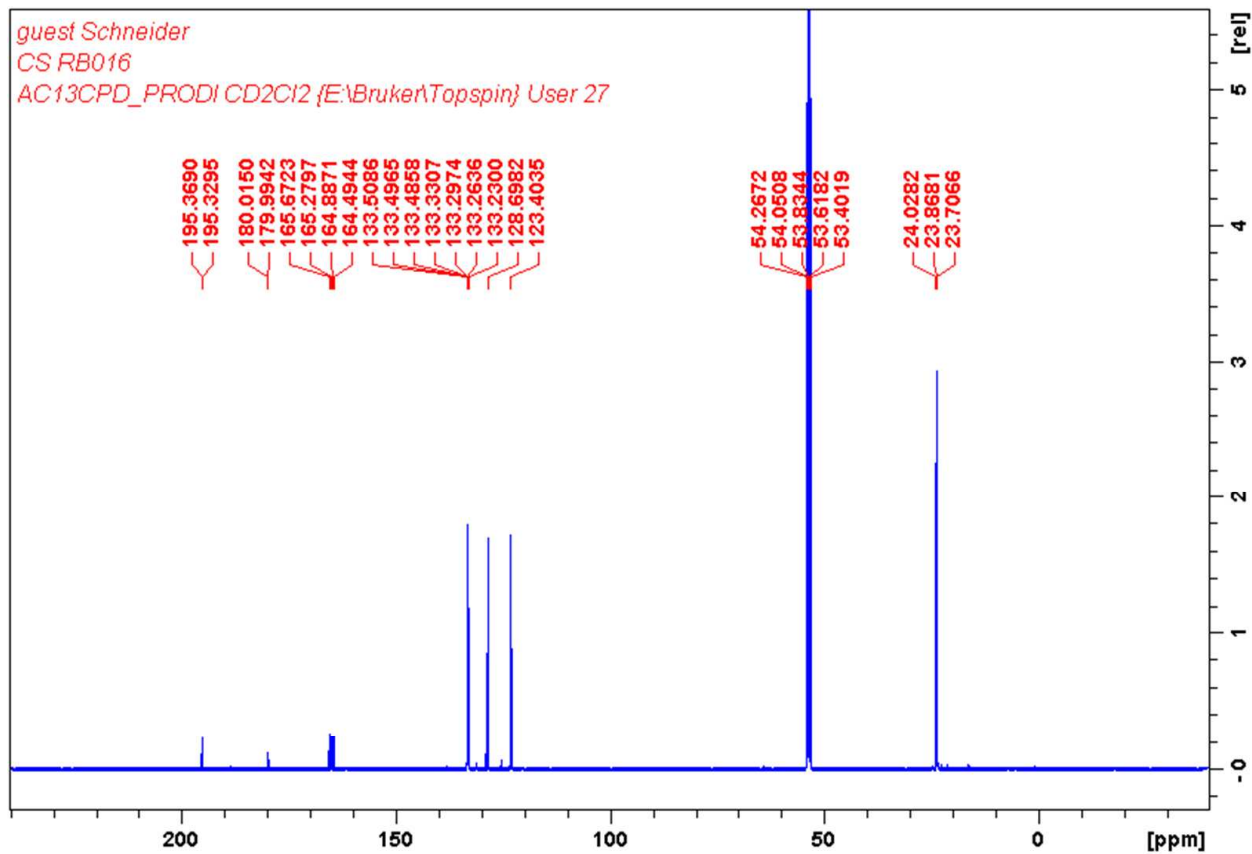

Figure S20. ${ }^{13} \mathrm{C}\left\{{ }^{1} \mathrm{H}\right\}$ NMR spectrum of 2e. The signal at 53.84 represents the $\mathrm{CD}_{2} \mathrm{Cl}_{2}$ signal and the signal at 128.69 can be assigned to benzene from the preparation. 


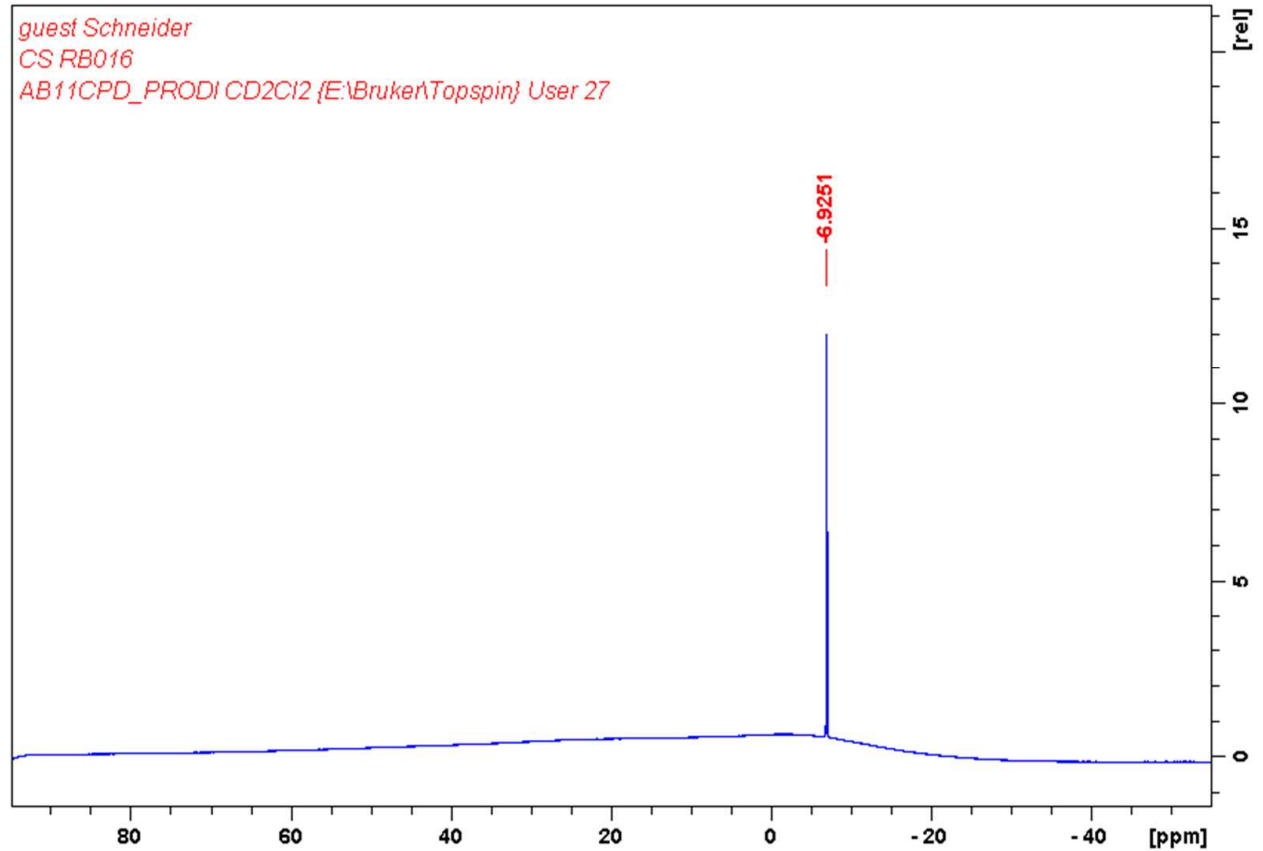

Figure S21. ${ }^{11} \mathrm{~B}\left\{{ }^{1} \mathrm{H}\right\}$ NMR spectrum of $\mathbf{2 e}$.

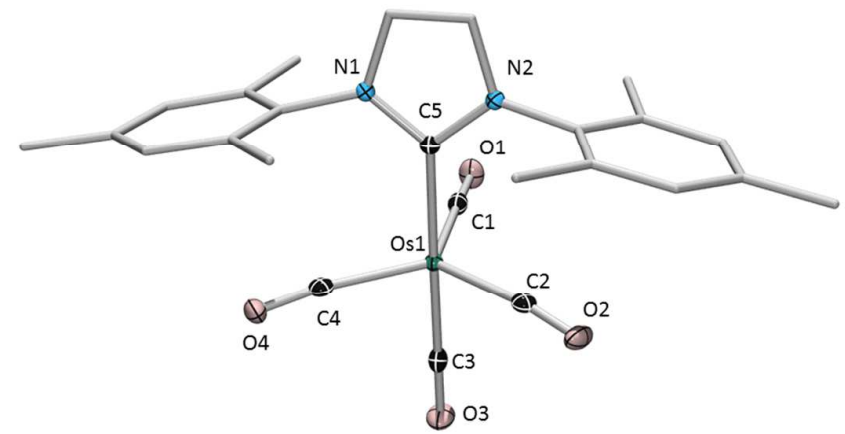

Figure S22. Molecular structure of $\mathbf{1 b}$ in the solid state. Ellipsoids are shown at the $50 \%$ probability level. Hydrogen atoms and some ellipsoids of the ligands are omitted for clarity. Selected bond length $[\AA]$ and angles []: Os1-C5 213.8(3), C5-Os1-C3 177.01(11). 


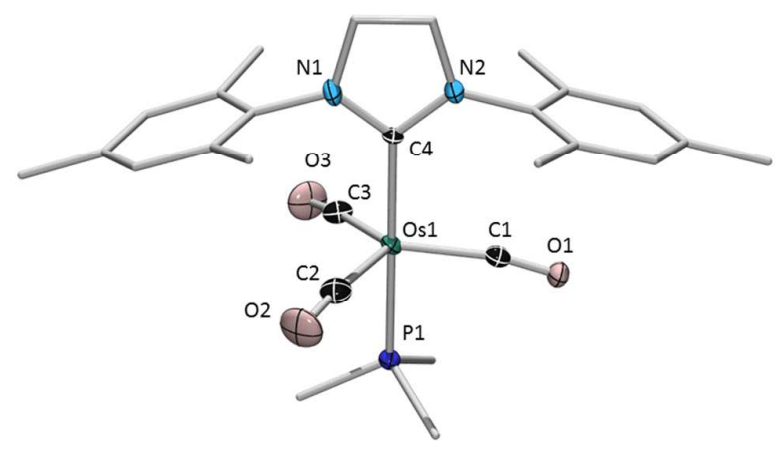

Figure S23. Molecular structure of $\mathbf{1 d}$ in the solid state. Ellipsoids are shown at the $50 \%$ probability level. Hydrogen atoms and some ellipsoids of the ligands are omitted for clarity. Selected bond length $[\AA]$ and angles []: Os1-C4 213.6(1), Os1-P1 233.5(2), C4-Os1-P1 179.7(1). 